\title{
A Tentative Analysis of the Rectangular Horizontal- slot Microstrip Antenna
}

\author{
Md. Tanvir Ishtaique ul Huque ${ }^{1}$ and Md. Imran Hasan $^{2}$ \\ Department of Electronics and Telecommunication Engineering, Rajshahi University of Engineering \& Technology \\ Rajshahi 6204, Bangladesh
}

\begin{abstract}
In this paper, we have presented a new type of microstrip antenna mentioned as rectangular horizontal-slot patch antenna. Our main motto is to design a novel antenna which has the simplicity in structure and higher return loss. We have followed a tentative approach which leads us to an exceptional result, better than conventional one and the experimental outcomes result some guidelines for further practice. Here all of these antennas were analyzed by using GEMS (General Electro-Magnetic Solver) commercial software from 2COMU (Computer and Communication Unlimited).
\end{abstract}

Keywords-GEMS; Microstrip antenna; Rectangular horizontal slot antenna; Return loss; Slot antenna; antenna

\section{INTRODUCTION}

Microstrip patch antennas are popular, because they have some advantages due to their conformal and simple planar structure. They allow all the advantages of printed-circuit technology. A vast number of papers are available on the investigation of various aspects of microstrip antennas $[1,6,7$, $8,10,11,12,13,14,15$, and 16].

The term "Microstrip" comes because the thickness of this metallic strip is in micro meter range. The key features of a microstrip antenna are relative ease of construction, light weight, low cost and either conformability to the mounting surface or, at least, an extremely thin protrusion from the surface $[2,5]$. These criteria make it popular in the field of wireless communication. Microstrip antennas are the first choice for this high frequency band due to its light weight, low cost, and robustness.

Microstrip patch elements are available in various configurations $[2,3,5]$. But the most common is the rectangular patch element. In this paper we have presented a new type of rectangular patch antenna mentioned as rectanguar slot patch antenna. We have introduced slots in it and examined the effect of it. Here we have only considered the return loss as the performance parameter. Return loss is a measure of how well the antenna is matched or how much power is going to be used effectively [5].

A high return loss is always desirable.This paper focus the design procedure, characteristic and the corresponding performance analysis of both the conventional rectangular antenna and newly introduced rectangular horizontal-slot antenna and provides a mean to choose the effective one based on their performance parameter.
Here all of these antennas have been designed simulated by using the GEMS (General Electro-Magnetic Solver) version 7.71.01 simulator. GEMS package includes a time domain solver based on the parallel conformal FDTD.

The proposed antennas are designed by using Taconic TLY -5 dielectric substrate with permittivity, $\varepsilon_{\mathrm{r}}=2.2$ and height, $\mathrm{h}=1.588 \mathrm{~mm}$. These designed antennas are promising to be a good candidate for the wireless applications due to the simplicity in structure, ease of fabrication and higher return loss.

\section{Antenna Configuration And Design}

Microstrip patch antenna, illustrated in Figure 1, consists of very thin metallic strip (patch) placed on ground plane where the thickness of the metallic strip is restricted by $\mathrm{t}<<\lambda_{0}$ and the height is restricted by $0.0003 \lambda_{0} \leq \mathrm{h} \leq 0.05 \lambda_{0}[9,13,14]$. The microstrip patch is designed so that its radiation pattern maximum is normal to the patch. For a rectangular patch, the length $\mathrm{L}$ of the element is usually $\lambda_{0} / 3<\mathrm{L}<\lambda_{0} / 2[9,13,14]$.

There are numerous dielectric substrates that can be used for the design of microstrip antennas and their dielectric constants are usually in the range of $2.2 \leq \varepsilon_{\mathrm{r}} \leq 12[5,9]$. To implement the microstrip antennas usually Fr-4 $\left(\varepsilon_{\mathrm{r}}=4.9\right)$, Rogers TMM 4( $\left.\varepsilon_{\mathrm{r}}=4.5\right)$, Taconic TLY-5 $\left(\varepsilon_{\mathrm{r}}=2.2\right)$, Alumina $(96 \%)\left(\varepsilon_{\mathrm{r}}=9.4\right)$, Teflon(PTFE) $\left(\varepsilon_{\mathrm{r}}=2.08\right)$, Arlon AD $5\left(\varepsilon_{\mathrm{r}}=5.1\right)$ dielectric materials are used as the substrate [ 2, 5].

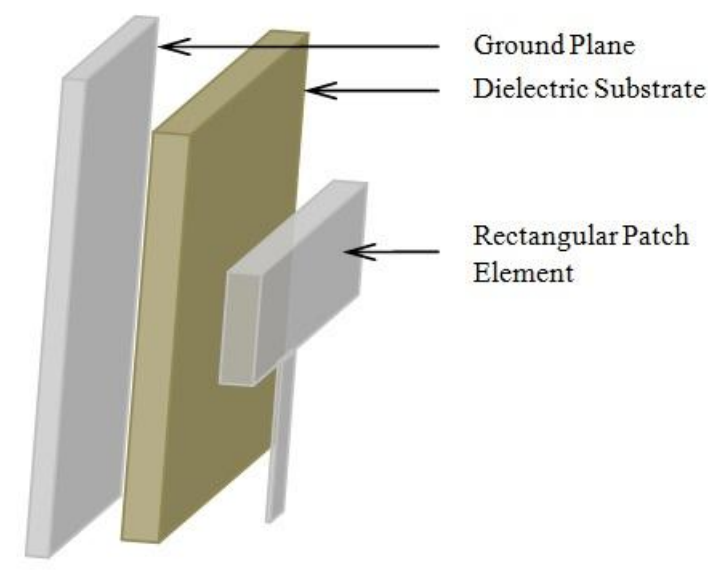

Fig. 1. Single element Rectangular microstrip patch antenna. 
The Performance of the microstrip antenna depends on its dimension. Depending on the dimension the operating frequency, radiation efficiency, directivity, return loss and other related parameters are also influenced [3,4]. Here, in this paper, a tentative analysis is made to find out the effect of introducing slots in the rectangular microstrip antenna and that leads to a comparative investigation between the rectangular microstrip antenna and rectangular horizontal-slot microstrip antenna.

For an efficient radiation a practical width of the Rectangular patch element becomes [2, 3, and 5]

$$
w=\frac{1}{2 f_{r} \sqrt{\mu_{0} \varepsilon_{0}}} \times \sqrt{\frac{2}{\varepsilon_{r}+1}}
$$

And the length of the antenna becomes [2, 3, 5]

$$
L=\frac{1}{2 f_{r} \sqrt{\varepsilon_{e f f}} \sqrt{\varepsilon_{0} \mu_{0}}}-2 \Delta L
$$

Where

$$
\begin{aligned}
& \Delta L=0.41 h \frac{\varepsilon_{\text {eff }}+0.3}{\varepsilon_{\text {eff }}-0.258} * \frac{\left(\frac{w}{h}+0.264\right)}{\left(\frac{w}{h}+0.8\right)} \\
& \varepsilon_{\text {eff }}=\frac{\varepsilon_{r}+1}{2}+\frac{\varepsilon_{r}-1}{2 \sqrt{1+12 \frac{h}{w}}}
\end{aligned}
$$

Where, $\lambda$ is the wave length, $f_{\mathrm{r}}$ (in $\mathrm{Hz}$ ) is the resonant frequency, $\mathrm{L}$ and $\mathrm{W}$ are the length and width of the patch element, in mm, respectively and $\varepsilon_{\mathrm{r}}$ is the relative dielectric constant.

In the following Fig. 2, Fig. 3 and Fig. 4 the antennas, mentioned as Antenna Type I, Antenna Type II and Antenna Type III respectively, are the single element rectangular microstrip antenna, where the quarter wavelength transformer method $[2,5,15,16]$ is used to match the impedance of the patch element with the transmission line. Here equation no 1 and 2 have been used to design all of these antennas.

Theoretically Antenna Type I, Antenna Type II and Antenna Type III have been designed to be operated in $8 \mathrm{GHz}$, $11 \mathrm{GHz}$ and $12 \mathrm{GHz}$ operating frequency respectively. In each Antenna type, there are two diffreent models- one is conventional rectangular microstrip patch antenna and another one is the rectangular-slot microstrip patch antenna. In the rectangular-slot microstrip patch antenna, each slot has 0.5 $\mathrm{mm}$ width, $0.5 \mathrm{~mm}$ separation distance from the both ends of the patch element and two successive slots are also separated by a distance of $0.5 \mathrm{~mm}$.

\section{Antenna Analysis And Simulation Result}

In this paper, it is considered that the substrate permittivity of the antenna is $\varepsilon_{\mathrm{r}}=2.2$ (Taconic TLY-5) and substrate thickness is $1.588 \mathrm{~mm}$.

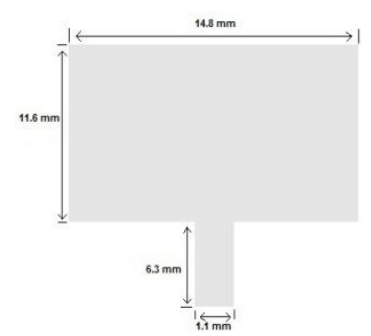

(a)

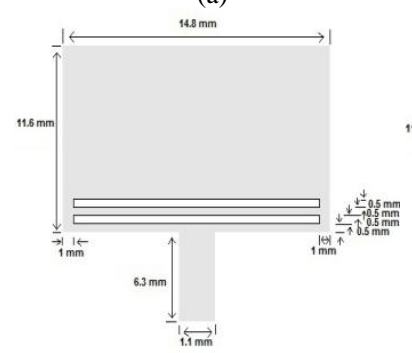

(c)

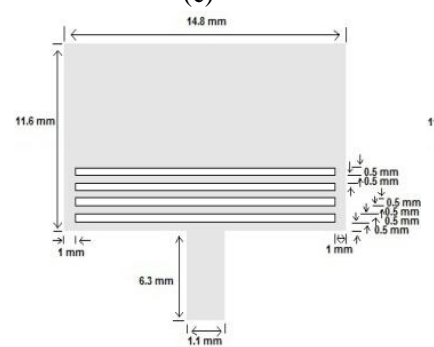

(e)

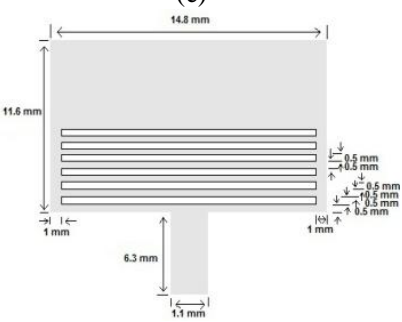

(g)

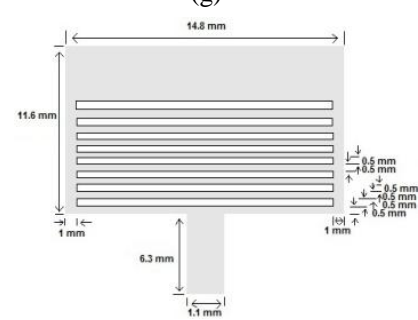

(i)

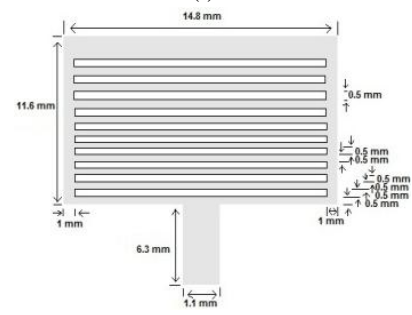

(k)

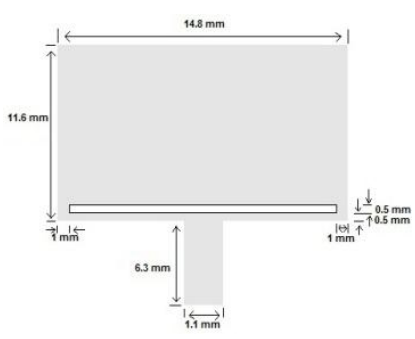

(b)

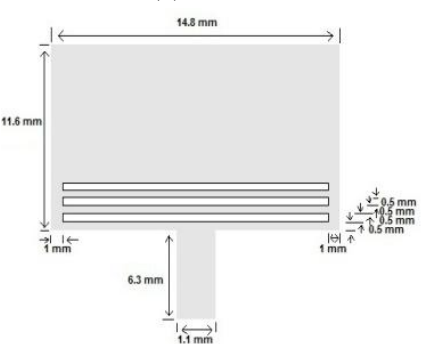

(d)

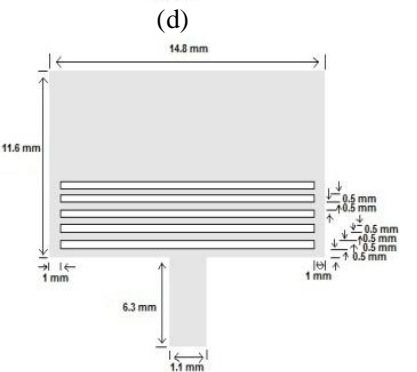

(f)

(h)

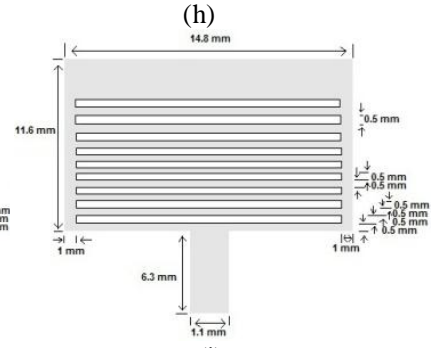

(j)

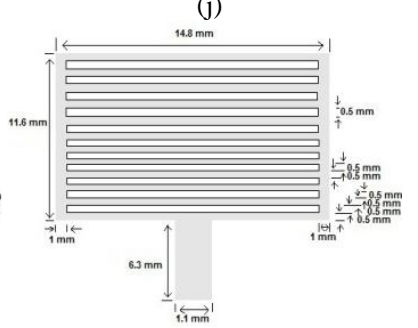

(1)

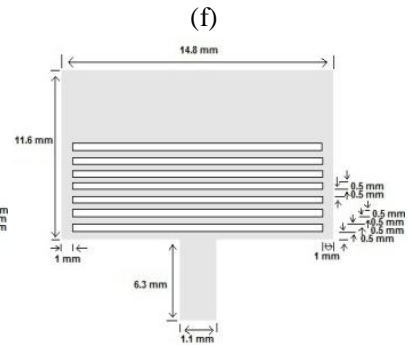

Fig. 2. Single element rectangular microstrip patch antenna (a) without slot and with (b) one slot (c) two slots (d) three slots (e) four slots (f) five slots (g) six slots (h) seven slots (i) eight slots (j) nine slots (k) ten slots (l) eleven slots. (Antenna Type I). 


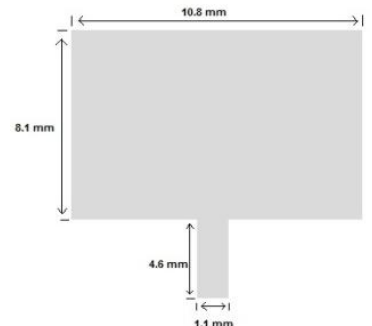

(a)

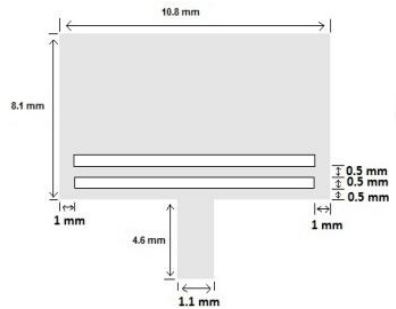

(c)

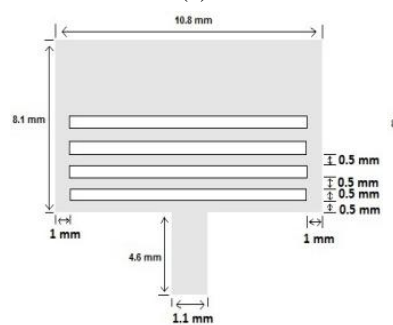

(e)

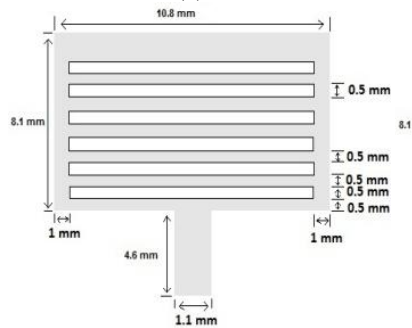

(g)

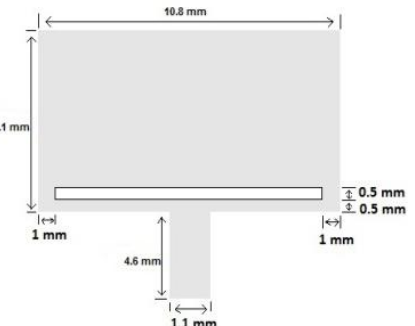

(b)

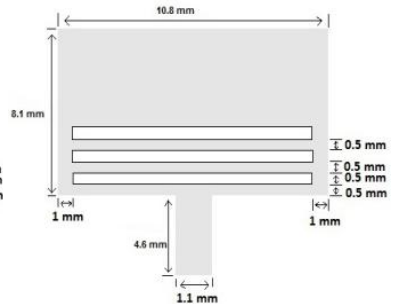

(d)

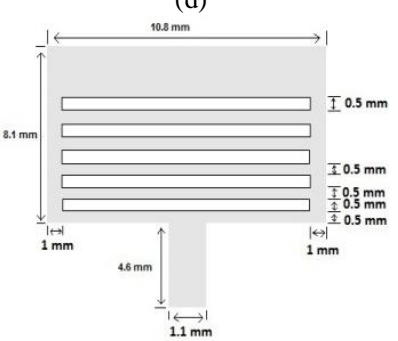

(f)

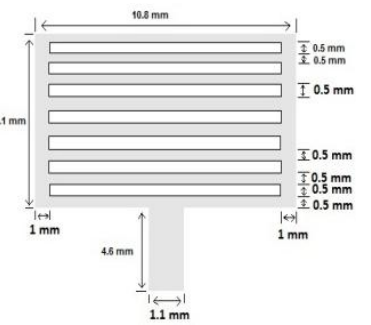

(h)
Fig. 3. Single element Rectangular microstrip patch antenna (a) without slot and with (b) one slot (c) two slots (d) three slots (e) four slots (f) five slots (g) six slots (h) seven slots. (Antenna Type II).

After simulation, as shown in Fig. 4, we found that, return loss is $-33.06 \mathrm{~dB}$ at $7.5 \mathrm{GHz}$ for the single element rectangular patch antenna. Simulation shows that the return loss is increased with introducing slot in the microstrip antenna and we get the maximum return loss $-48.86 \mathrm{~dB}$ at $12.7 \mathrm{GHz}$ operating frequency having three slots in the rectangular patch antenna.
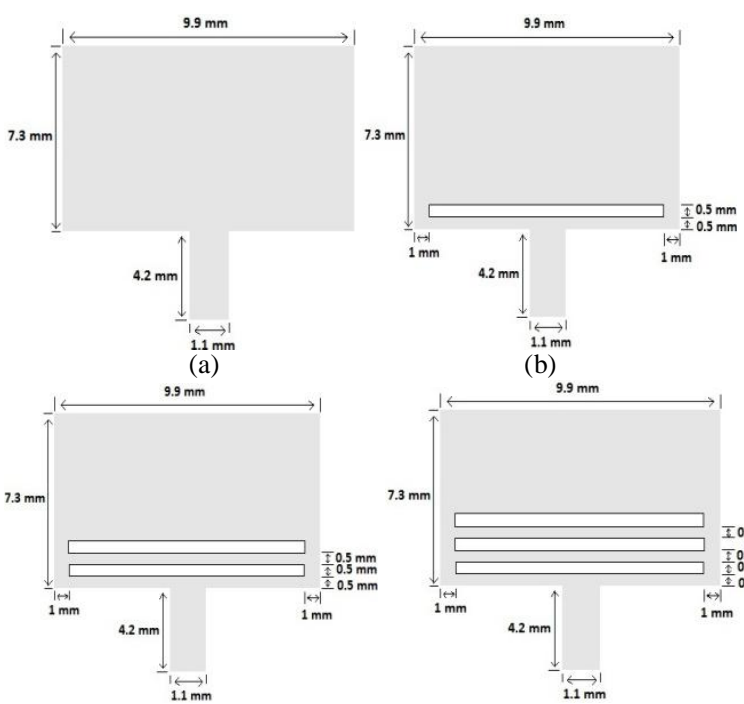

(b)

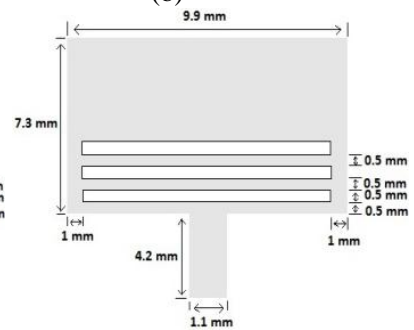

(c)

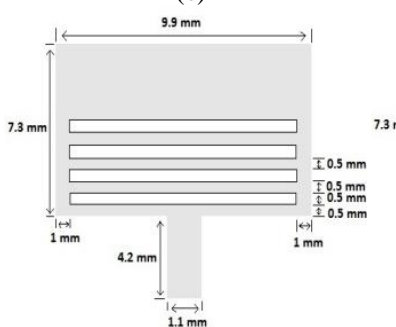

(e)

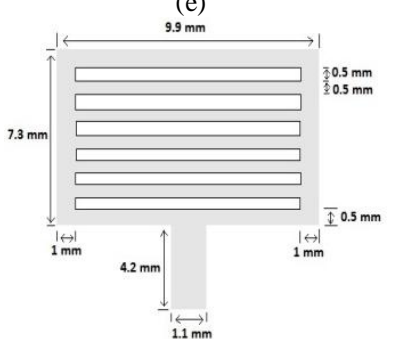

(g)

Fig. 4. Single element Rectangular microstrip patch antenna (a) without slot and with (b) one slot (c) two slots (d) three slots (e) four slots (f) five slots (g) six slots. (Antenna Type III).

Fig. 5 and Fig. 6 also show the same kind of manner as the Fig. 4. According to Fig. 5, return loss is $-16.48 \mathrm{~dB}$ at 10.5 $\mathrm{GHz}$ for the single element rectangular patch antenna and because of introducing slot in the microstrip antenna; we get the maximum return loss $-27.25 \mathrm{~dB}$ at $16.3 \mathrm{GHz}$ operating frequency having two slots in the rectangular patch antenna. 


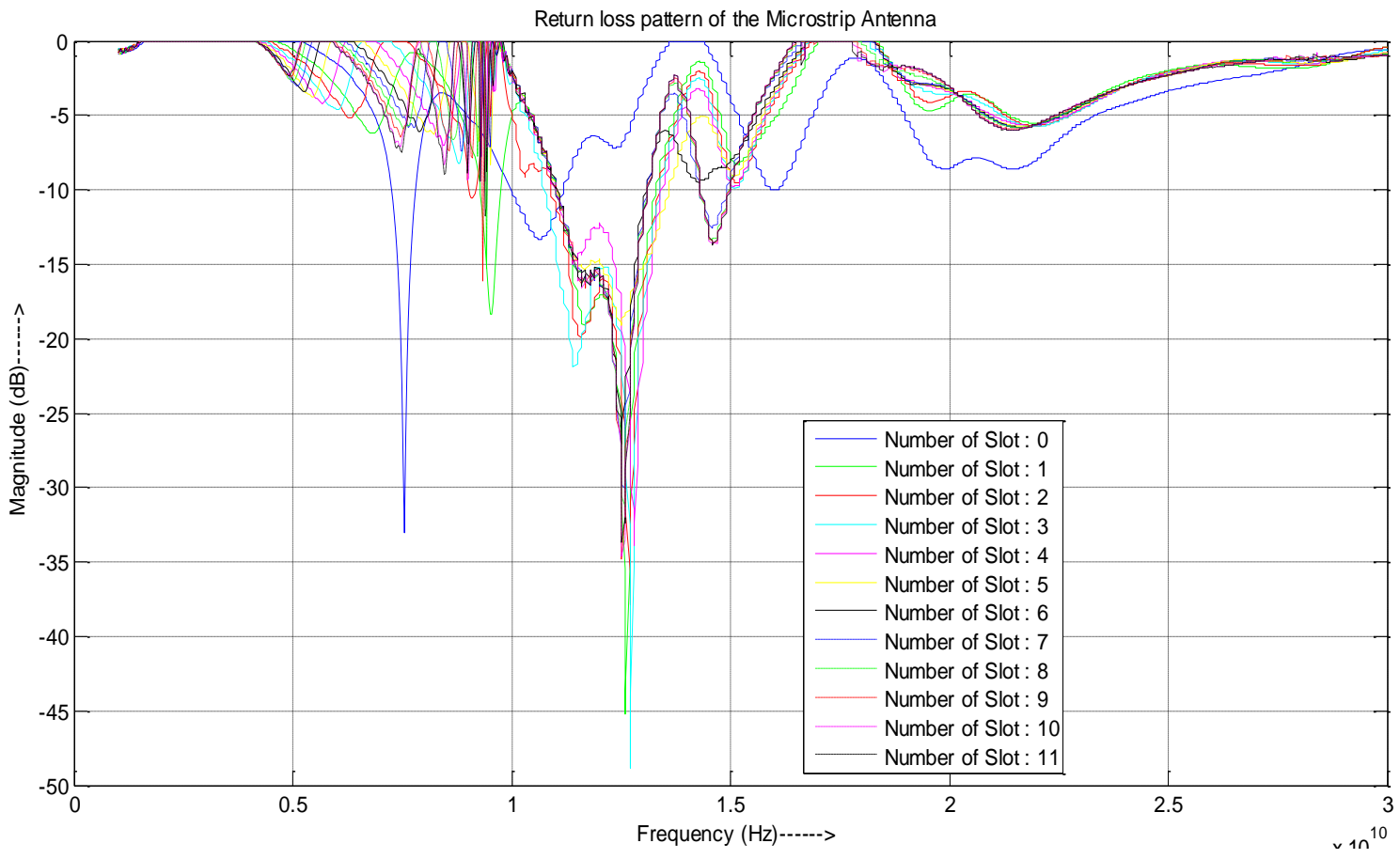

Fig. 5. Return loss pattern variation with respect to the frequency at different number of horizontal slots of Antenna Type I.

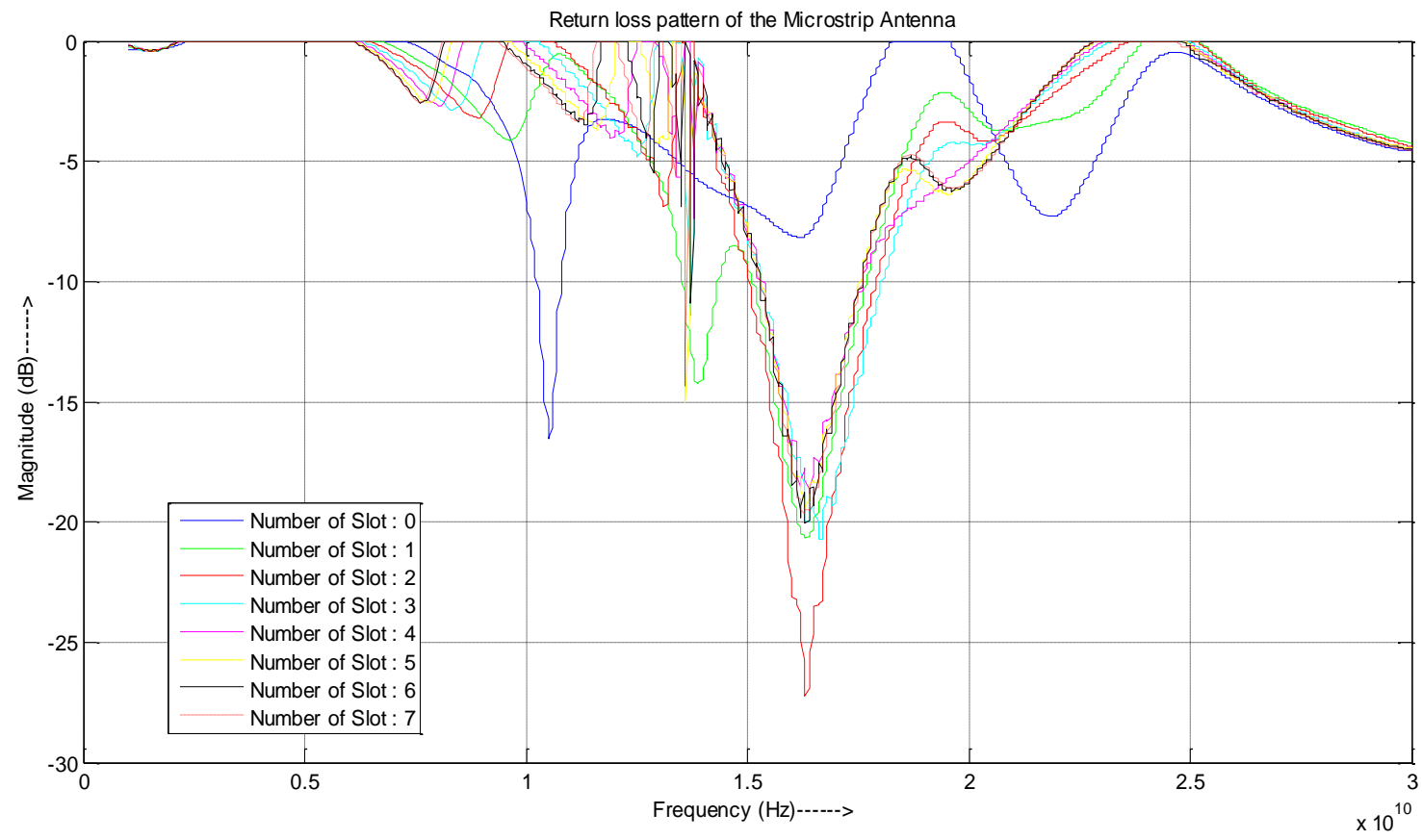

Fig. 6. Return loss pattern variation with respect to the frequency at different number of horizontal slots of Antenna Type II. 


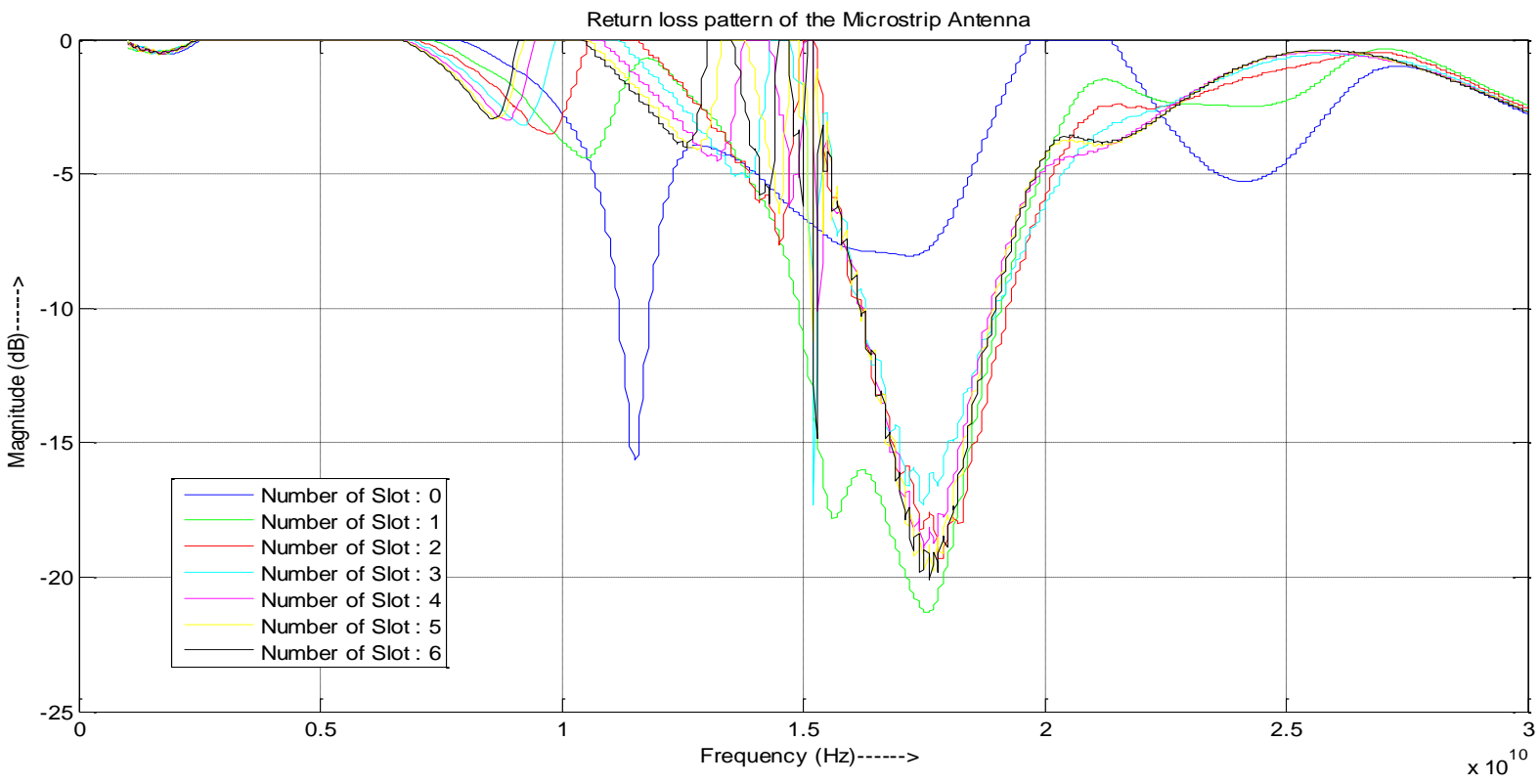

Fig. 7. Return loss pattern variation with respect to the frequency at different number of horizontal slots of Antenna Type III.

Return loss pattern variation with respect to the frequency at different number of horizontal slots of Antenna Type III.

Fig. 6 states that return loss is $-15.66 \mathrm{~dB}$ at $11.5 \mathrm{GHz}$ for the single element rectangular patch antenna. Simulation also shows that the return loss is increased with introducing slot in the microstrip antenna and we get the maximum return loss $21.3 \mathrm{~dB}$ at $17.6 \mathrm{GHz}$ operating frequency having three slots in the rectangular patch antenna.

In this paper, we have tried to find out a microstrip antenna having maximum return loss to get maximum efficiency and our investigation show that by introducing slot in the rectangular microstrip antenna we get greater return loss than the conventional rectangular patch antenna.

A comparative analysis of Fig. 4, Fig. 5 and Fig. 6 lead us to the Fig. 7, Fig. 8 and Fig. 9 which depict the effect of number of slots of the Antenna Type I, Antenna Type II and Antenna Type III respectively, from which we can easily understand that how many number of slots are necessary in each type of antenna to get the maximum return loss.

From Fig. 7, it is clear that for the Antenna Type I, having the slot of $0.5 \mathrm{~mm}$ width with the prescribed configuration; to get the maximum return loss three (3) slots are required. Fig. 8 and Fig. 9 also enunciate that for the Antenna Type II and Antenna Type III, having the slot of $0.5 \mathrm{~mm}$ width with the prescribed configuration, to get the maximum return loss two (2) slots and one (1) slot are required respectively.

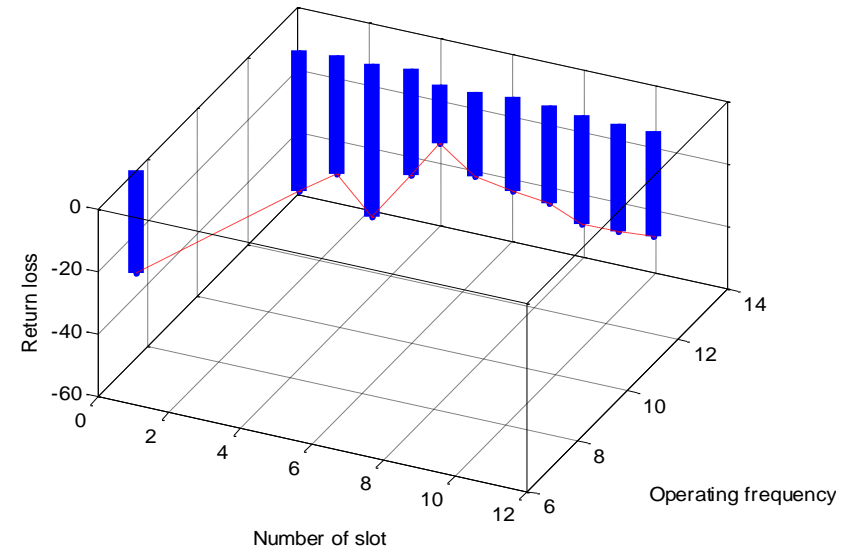

Fig. 8. Variation of the Maximum Return Loss and the Operating frequency with respects to the number of slots of Antenna Type I

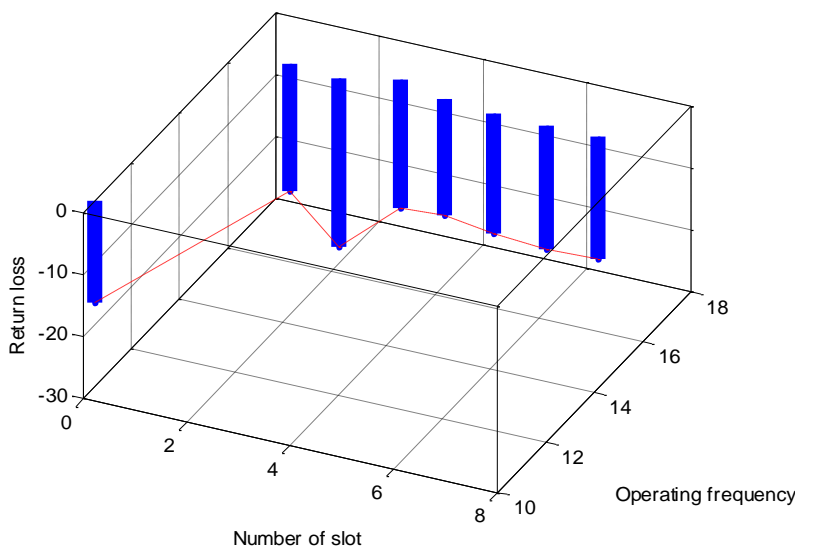

Fig. 9. Variation of the Maximum Return Loss and the Operating frequency with respects to the number of slots of Antenna Type II 


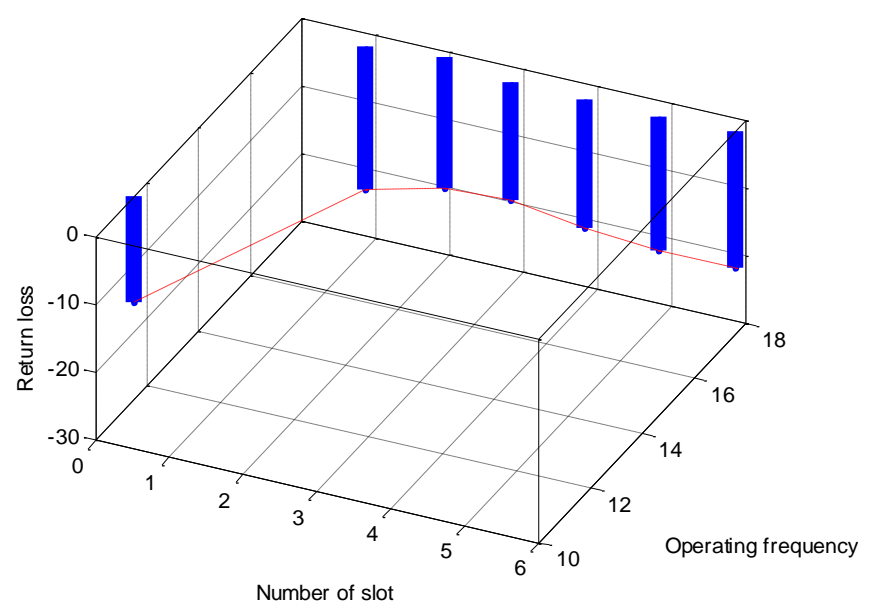

Fig. 10. Variation of the Maximum Return Loss and the Operating frequency with respects to the number of slots of Antenna Type III

\section{Measurements And Result Discussion}

Our whole experimental outcomes conduct us to to the following Table I, Table II and Table III for three different types of antennas known as Antenna Type I, Antenna Type II and Antenna Type III respectively. These tables are the fruits, in brief, of our full tentative analysis.

Here we have followed a tentative approach to find out the effect of slot in the single element rectangular patch antenna. Our experimental investigation leads us to the following outcomes depending on the data available in the Table I, Table II and Table III. All of these observations give us an optimum result about the selection of the slot in the patch element.

- Return loss increases with increasing antenna area or in turn slot length. Such as

For $(11.6 \mathrm{~mm} \times 14.8 \mathrm{~mm})$ Antenna Type I having slot length of $12.8 \mathrm{~mm}$ Maximum Return loss is $-48.86 \mathrm{~dB}$.

For $(8.1 \mathrm{~mm} \times 10.8 \mathrm{~mm})$ Antenna Type II having slot length of $8.8 \mathrm{~mm}$ Maximum Return loss is $-27.25 \mathrm{~dB}$.

For $(7.3 \mathrm{~mm} \times 9.9 \mathrm{~mm})$ Antenna Type III having slot length of $7.9 \mathrm{~mm}$ Maximum Return loss is $-21.3 \mathrm{~dB}$.

- After observation, we get that the operating frequency of the microstrip antenna (without slot) is always 5.5 $\mathrm{GHz}$ less than the estimated one. Such as

For Antenna Type I, Maximum return loss is obtained at $7.5 \mathrm{Ghz}$, but it was designed for $8 \mathrm{GHz}$.

For Antenna Type II, Maximum return loss is obtained at 10.5 Ghz, but it was designed for $11 \mathrm{GHz}$.

For Antenna Type IIII, Maximum return loss is obtained at $11.5 \mathrm{Ghz}$, but it was designed for $12 \mathrm{GHz}$.

TABLE I. GEOMETRIC Gestalt AND SimUlation RESUlt of THE “ANTENNA TyPe I"

\begin{tabular}{|c|c|c|c|c|c|c|c|}
\hline $\begin{array}{l}\text { Antenna Length } \\
(\mathrm{mm})\end{array}$ & $\begin{array}{l}\text { Antenna } \\
\text { Width (mm) }\end{array}$ & $\begin{array}{l}\text { Slot Width } \\
(\mathrm{mm})\end{array}$ & $\begin{array}{l}\begin{array}{l}\text { Slot } \\
\text { Length } \\
(\mathrm{mm})\end{array} \\
\end{array}$ & $\begin{array}{l}\text { Number of } \\
\text { Slots }\end{array}$ & $\begin{array}{l}\text { Theoretically desired } \\
\text { Frequency }(\mathbf{G H z})\end{array}$ & $\begin{array}{l}\text { Obtained } \\
\text { Frequency }(\mathbf{G H z}) \\
\text { in Simulation } \\
\end{array}$ & $\begin{array}{lr}\text { Max. } & \text { Return } \\
\text { Loss. } & \text { in } \\
\text { Simulation }(\mathbf{d B}) \\
\end{array}$ \\
\hline \multirow{12}{*}{11.6} & \multirow{12}{*}{14.8} & \multirow{12}{*}{0.5} & \multirow{12}{*}{12.8} & 0 & 8 & 7.55 & -33.06 \\
\hline & & & & 1 & 8 & 12.6 & -45.17 \\
\hline & & & & 2 & 8 & 12.7 & -37.83 \\
\hline & & & & 3 & 8 & 12.7 & -48.86 \\
\hline & & & & 4 & 8 & 12.8 & -33.9 \\
\hline & & & & 5 & 8 & 12.5 & -19.09 \\
\hline & & & & 6 & 8 & 12.5 & -27.08 \\
\hline & & & & 7 & 8 & 12.6 & -30.11 \\
\hline & & & & 8 & 8 & 12.6 & \begin{tabular}{|l|}
-31.3 \\
\end{tabular} \\
\hline & & & & 9 & 8 & 12.5 & -34.77 \\
\hline & & & & 10 & 8 & 12.5 & -34.6 \\
\hline & & & & 11 & 8 & 12.5 & -33.6 \\
\hline
\end{tabular}

TABLE II. GeOMETRIC GeSTALT AND SimUlation ResUlt OF THE “ANTENNA TyPe II”

\begin{tabular}{|c|c|c|c|c|c|c|c|}
\hline $\begin{array}{l}\text { Antenna } \\
\text { Length } \\
(\mathrm{mm})\end{array}$ & $\begin{array}{l}\text { Antenna } \\
\text { Width (mm) }\end{array}$ & $\begin{array}{l}\text { Slot Width } \\
(\mathbf{m m})\end{array}$ & $\begin{array}{l}\text { Slot Length } \\
(\mathrm{mm})\end{array}$ & $\begin{array}{l}\text { Number of } \\
\text { Slots }\end{array}$ & $\begin{array}{l}\text { Theoretically desired } \\
\text { Frequency }(\mathrm{GHz})\end{array}$ & $\begin{array}{l}\text { Obtained Frequency } \\
(\mathbf{G H z}) \text { in Simulation }\end{array}$ & $\begin{array}{l}\text { Max. Return Loss. in } \\
\text { Simulation (dB) }\end{array}$ \\
\hline \multirow{8}{*}{8.1} & \multirow{8}{*}{10.8} & \multirow{8}{*}{0.5} & \multirow{8}{*}{8.8} & 0 & 11 & 10.5 & -16.48 \\
\hline & & & & 1 & 11 & 16.4 & -20.6 \\
\hline & & & & 2 & 11 & 16.3 & -27.25 \\
\hline & & & & 3 & 11 & 16.7 & -20.69 \\
\hline & & & & 4 & 11 & 16.4 & $\begin{array}{l}-18.8 \\
\end{array}$ \\
\hline & & & & 5 & 11 & 16.3 & -19.49 \\
\hline & & & & 6 & 11 & 16.3 & -20.05 \\
\hline & & & & 7 & 11 & 16.3 & -19.68 \\
\hline
\end{tabular}


TABLE III. GeOMETRIC GeStalt AND Simulation RESUlt OF THE “ANTENNA TyPe III”

\begin{tabular}{|c|c|c|c|c|c|c|c|}
\hline $\begin{array}{l}\text { Antenna } \\
\text { Length }(\mathrm{mm})\end{array}$ & $\begin{array}{l}\text { Antenna } \\
\text { Width }(\mathrm{mm})\end{array}$ & $\begin{array}{l}\text { Slot Width } \\
(\mathrm{mm})\end{array}$ & $\begin{array}{l}\text { Slot Length } \\
(\mathrm{mm})\end{array}$ & $\begin{array}{l}\text { Number of } \\
\text { Slots }\end{array}$ & $\begin{array}{l}\text { Theoretically desired } \\
\text { Frequency }(\mathrm{GHz})\end{array}$ & $\begin{array}{l}\text { Obtained Frequency } \\
(\mathrm{GHz}) \text { in Simulation }\end{array}$ & $\begin{array}{l}\text { Max. Return Loss. in } \\
\text { Simulation (dB) }\end{array}$ \\
\hline \multirow{7}{*}{ ק } & \multirow{7}{*}{9.9} & \multirow{7}{*}{0.5} & \multirow{7}{*}{7.9} & 0 & 12 & 11.5 & -15.66 \\
\hline & & & & 1 & 12 & 17.6 & \begin{tabular}{|l|}
-21.3 \\
\end{tabular} \\
\hline & & & & 2 & 12 & 17.8 & -19.29 \\
\hline & & & & 3 & 12 & 17.5 & -17.31 \\
\hline & & & & 4 & 12 & 17.5 & -18.92 \\
\hline & & & & 5 & 12 & 17.5 & -19.75 \\
\hline & & & & 6 & 12 & 17.6 & -20.11 \\
\hline
\end{tabular}

- When we add slot in an Antenna, we find that the Maximum Return Loss (MRL) is shifted to a different operating frequency, depending on the number of slots. The shifted operating frequency becomes

Where

$$
\mathrm{F}_{\mathrm{M}}=\mathrm{F}_{\mathrm{I}}+\mathrm{F}_{\mathrm{S}}
$$

$\mathrm{F}_{\mathrm{M}}=$ Shifted operating frequency having the MRL of the Slotted Antenna.

$F_{I}=$ Estimated operating frequency for which the Antenna has been designed.

$\mathrm{F}_{\mathrm{S}}=$ The amount of frequency shifting which is maximum up to $5.8 \mathrm{GHz}$.

As an example, for the Antenna Type III, MRL -21.3dB was found in $17.6 \mathrm{Ghz}$ operating frequency whereas the antenna was designed to operate at $12 \mathrm{GHz}$. Here, $\mathrm{F}_{\mathrm{M}}=17.6 \mathrm{Ghz}, \mathrm{F}_{\mathrm{I}}=$ $12 \mathrm{Ghz}$ and $\mathrm{F}_{\mathrm{S}}=5.6 \mathrm{Ghz}$.

- Here we have introduced the concept of slot in the microstrip antenna to get the maximum return loss and our experiment shows that we need to use maximum four(4) slots to get the maximum return loss. Such as

For Antenna Type I, when the number of slot is 3 the maximum return loss becomes $-48.86 \mathrm{~dB}$.

For Antenna Type II, when the number of slot is 2 the maximum return loss becomes $-27.25 \mathrm{~dB}$.

For Antenna Type III, when the number of slot is 1 the maximum return loss becomes $-21.3 \mathrm{~dB}$.

- Experimental statistics state that the difference of Maximum Return Loss between the slot and without slot antenna decreases with decreasing order of the microstrip antenna area. Such as,

For $(11.6 \mathrm{~mm} \times 14.8 \mathrm{~mm})$ Antenna Type I, Maximum Return loss is $-33.06 \mathrm{~dB}$ and after introducing slot when there are three(3) slots in the same antenna the maximum return loss becomes $-48.86 \mathrm{~dB}$. The difference in Return Loss between two conditions is $15.8 \mathrm{~dB}$.

For $(8.1 \mathrm{~mm} \times 10.8 \mathrm{~mm})$ Antenna Type II, Maximum Return loss is $-16.48 \mathrm{~dB}$ and after introducing slot when there are two(2) slots in the same antenna the maximum return loss becomes $-27.25 \mathrm{~dB}$. The difference in Return Loss between two conditions is $10.77 \mathrm{~dB}$.

For $(7.3 \mathrm{~mm} \times 9.9 \mathrm{~mm})$ Antenna Type III, Maximum Return loss is $-15.66 \mathrm{~dB}$ and after introducing slot when there is one (1) slot in the same antenna the maximum return loss becomes
-21.3 dB. The difference in Return Loss between two conditions is $5.64 \mathrm{~dB}$.

\section{CONCLUSION}

The unique feature of this microstrip antenna is its simplicity to get higher performance. In many applications, basically in wireless communication, it is necessary to design antennas with very high Return loss to meet the demand of long distance communication and the most common configuration to satisfy this demand is the microstrip antenna.

In our ongoing investigation, we have tried to find out the effect of slot in the microstrip antenna and that lead us to a remarkable result. Here we have invented a novel antenna, mentioned as rectangular horizontal slot patch antenna, which shows much higher return loss than the conventional rectangular patch antenna. In this paper, we have only focused some simulated result of introducing slots in the rectangular patch antenna where the slot width is fixed and the separation distance between two slots are also remained constant. We have experimented in three different cases and their outcomes are about similar.

We are still working on the rectangular horizontal as well as vertical slot patch antenna and investigating the effect of the variation of the slot size, separation distance between two slots in the microstrip antenna, with that inspiration to open a new horizon in the field on Antenna Technology.

\section{REFERENCES}

[1] R. J. Mailloux, J. F. Mcllvenna, N. P. Kernweis, "Microstrip array technology", IEEE Trans. Antenna Propagation Magazine, vol. 29, no. 1, pp. 25-27, 1981.

[2] C. A. Balanis, Antenna Engineering, $2^{\text {nd }}$ ed., Willey, 1982.

[3] T. A. Millikgan, Modern Antenna Design, $2^{\text {nd }}$ ed., IEEE Press, John Wiley \& Sons inc., 2007.

[4] M. I. Skolnik, Introduction to RADAR System, $3^{\text {rd }}$ ed., McGraw Hill Higher Education, 2000.

[5] R. Garg, P. Bhartia, I. Bahl, A. Ittipiboon, Microstrip Antenna Design Handbook, Artech House inc., 2001.

[6] W. L. Stutzman, "Estimating directivity and gain of antennas", IEEE Antennas and Propagation Magazine, Vol. 40, No. 4,pp 7-11, August, 1998.

[7] H. J. Visser, Array and Phased Array Antenna Basics, John Wiley \& Sons Ltd., 2005.

[8] Muhammad Mahfuzul Alam, Md. Mustafizur Rahman Sonchoy, and Md Osman Goni, "Design and Performance Analysis of Microstrip Array Antenna", Progress In Electromagnetic Research Symposium Proceedings, Moscow, Russia, Aug. 18-21, 2009.

[9] Md. Shihabul Islam and Md. Tanvir Ishtaique-ul Huque, "Design and Performance Analysis of Microstrip Array Antenna", B.Sc. Engineering thesis, Dept. of ETE, Rajshahi University Of Engineering \& Technology(RUET), Rajshahi, Bangladesh, April, 2010. 
[10] K. Shambavi, C. Z. Alex, T. N. P. Krishna, "Design and Analysis of High Gain Milimeter Wave Microstrip Antenna Array for Analysis of High Gain Millimeter Wave Microstrip Anteanna Array for Wireless Application", J. of Applied Theoretical and Information Technology(JATIT), 2009.

[11] Asghar Keshtkar, Ahmed Keshtkar and A. R. Dastkhosh, "Circular Microstrip Patch Array Antenna for C-Band Altimeter System", Int. J. of Antenna and Propagation, article ID 389418, Nov., 2007. (doi:10.1155/2008/389418)

[12] M. F. Islam, M. A. Mohd. Ali, B. Y. Majlis and N. Misran, "Dual Band Microstrip Patch Antenna for Sar Applications", Australian Journal of Basic and Applied Sciences, 4(10): 4585- 4591, 2010.

[13] Md. Tanvir Ishtaique-ul Huque, Md. Al-Amin Chowdhury, Md. Kamal Hosain, Md. Shah Alam, "Performance Analysis of Corporate Feed Rectangular Patch Element and Circular Patch Element 4x2 Microstrip Array Antennas", Int. J. of Advanced Computer Science and
Applications(IJACSA), vol. 2, no.8, pp. 16-21, 2011.

[14] Md. Tanvir Ishtaique-ul Huque, Md. Kamal Hosain, Md. Shihabul Islam, Md. Al-Amin Chowdhury, "Design and Performance Analysis of Microstrip Array Antennas with Optimum Parameters for X-band Applications", Int. J. of Advanced Computer Science and Applications (IJACSA), vol. 2, no. 4, pp. 81-87, 2011.

[15] Md. Tanvir Ishtaique-ul Huque, Md. Kamal Hosain, Mst. Fateha Samad, Muhammed Samsuddoha Alam, "Design and Simulation of a Low-cost and High Gain Microstrip Patch Antenna Arrays for the X-band Applications", Int. Conf. on Network Communication and Computer (ICNCC 2011), India, pp. 548- 552, March 19-20, 2011.

[16] Md. Tanvir Ishtaique-ul Huque, Md. Shihabul Islam, Mst. Fateha Samad, Md. Kamal Hosain, "Design and Performance Analysis of the Rectangular Spiral Microstrip Antenna and Its Array Configuration", 9th Int. Symp. on Antenna Propagation \& EM Theory (ISAPE 2010), China, pp. 219-221, Nov 29 - Dec 2, 2010. 